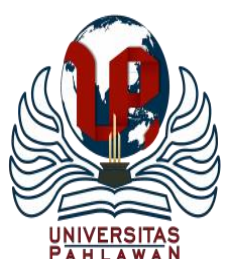

Jurnal Abdidas Volume 2 Nomor 4 Tahun 2021 Halaman 922-927

JURNAL ABDIDAS

http://abdidas.org/index.php/abdidas

\title{
Pelatihan Penataan Dan Penerangan Ruang Baca Di Sekolah PKBM Wiyata Utama
}

\author{
Triyanto Pangaribowo $^{1 凶}$, Trie Maya Kadarina ${ }^{2}$, Fadli Sirait ${ }^{3}$, Akhmad Wahyu Dani ${ }^{4}$, Fina Supegina ${ }^{5}$ \\ Teknik Elektro, Fakultas Teknik, Universitas Mercu Buana, Jakarta, Indonesia ${ }^{1,2,3,4,5}$ \\ E-mail : triyanto.pangaribowo@mercubuana.ac.id ${ }^{1}$ trie.maya@mercubuana.ac.id $^{2}$ \\ fadli.sirait@mercubuana.ac.id ${ }^{3}$ wahyu.dani@ mercubuana.ac.id ${ }^{4}$ \\ fina.supegina@mercubuana.ac.id ${ }^{5}$
}

\begin{abstract}
Abstrak
Kegiatan pengabdian masyarakat ini bertujuan untuk melakukan penataan dan penerangan ruang baca di sekolah PKBM Wiyata Utama yang terletak di daerah Kembangan Utara, Jakarta Barat. Pelatihan ini merupakan solusi terhadap permasahalan yang dihadapi pihak sekolah yaitu minimnya pemahaman dan pengetahuan mengenai penataan dan penerangan ruang baca yang baik. Tujuan penataan ini untuk memberikan kenyamanan pada siswa dan guru sehingga optimal dalam memanfaatkan ruang baca. Metode yang digunakan dalam kegiatan pengabdian ini meliputi identifikasi masalah dengan melakukan survei, pemaparan desain ruang baca secara online, tahap pelaksanaan kegiatan penataan, dan evaluasi kegiatan melalui kuisioner secara online. Hasil dari kegiatan ini, para guru dan siswa secara optimal melakukan kegiatan di ruang baca dengan penerangan lampu yang baik sehingga aman untuk mata. Hasil evaluasi kegiatan menunjukkan bahwa kegiatan sangat bermanfaat untuk menambah ilmu pengetahuan dan menjadi solusi dalam mengatasi permasalahan penataan di ruang baca sekolah.
\end{abstract}

Kata kunci: pelatihan, penataan, penerangan, ruang baca

\section{Abstract}

This community service activity aims to organize and lighting for the reading room at the Wiyata Utama PKBM school in the Kembangan Utara area, Jakarta Barat. This training is a solution to the problems faced by the school, namely the lack of understanding and knowledge about the arrangement and lighting of a good reading room. The purpose of this arrangement is to provide comfort for students and teachers so that they are optimal in utilizing the reading room. The methods used in this service activities include identifying problems by conducting surveys, presenting of reading room designs via online, implementing stage, and evaluating activities through online questionnaire. As a result of this activities, teachers and students optimally carry out activities in the reading room with good lighting for the eyes safety. The results of the activity evaluation show that the activity is very useful for increasing knowledge and being a solution in overcoming the problem of arrangement in the school reading room.

Keywords: training, arrangement, lighting, reading room

Copyright (c) 2021 Triyanto Pangaribowo, Trie Maya Kadarina, Fadli Sirait, Akhmad Wahyu Dani, Fina Supegina

$\triangle$ Corresponding author

Address : Universitas Mercu Buana

Email : triyanto.pangaribowo@mercubuana.ac.id

DOI : https://doi.org/10.31004/abdidas.v2i4.391

ISSN 2721- 9224 (Media Cetak)

ISSN 2721- 9216 (Media Online) 
923 Pelatihan Penataan Dan Penerangan Ruang Baca Di Sekolah PKBM Wiyata Utama - Triyanto Pangaribowo, Trie Maya Kadarina, Fadli Sirait, Akhmad Wahyu Dani, Fina Supegina

DOI: https://doi.org/10.31004/abdidas.v2i4.391

\section{PENDAHULUAN}

Ruang baca merupakan tempat kegiatan siswa dan guru dalam memperoleh bahan bacaan dan informasi dari berbagai jenis bahan pustaka dengan membaca (Hidayatullah, 2017). Ruang baca merupakan salah satu layanan perpustakaan yang penting, Sehingga penataan ruang baca akan mempengaruhi produktivitas, efisiensi, dan kenyamanan pemakai (Muhriani, Umran, \& Abdullah, 2016). Suasana ruang baca sangat penting agar dapat memberikan kenyamanan, atmosphere belajar yang menyenangkan dan dapat mempengaruhi psikologi pengguna sehingga minat bacanya meningkat (Susanti \& Budiono, 2014).

Ruang baca merupakan tempat yang biasanya dimiliki dari setiap sekolah. Salah satu faktor untuk mendukung optimal fungsi sebuah ruang adalah dari sisi pencahayaan (Kurniasih \& Saputra, 2019). Sistem pencahayaan yang baik dari sebuah ruang baca adalah memiliki lampu dengan kualitas baik. Intensitas pencahayaan memiliki pengaruh yang besar terhadap kesehatan mata (Wiyanti \& Martiana, 2015). Pencahayaan berfungsi sebagai penerang ruang untuk mendukung kegiatan yang berlangsung dalam ruang tersebut.

Pencahayan ruangan perlu dukungan lampu yang baik. Setiap ruangan harus memiliki pencahayaan yang baik dan berkualitas agar dapat menjaga kesehatan mata. Ada beberapa jenis lampu yang sering digunakan diantaranya yaitu Lampu Halogen dengan reflektor untuk memperkuat cahaya yang keluar (Agam, Yushardi, \& Prihandono, 2015). Lampu LED adalah lampu hemat energi yang memiliki penerangan yang baik, hemat biaya dan dapat mengurangi pemanasan global karena tidak menghasilkan panas seperti lampu pijar dan tidak berpotensi mengganggu kesehatan seperti lampu neon (Winardi, 2018).

Menyadari ruang baca sangat penting pada sebuah sekolah. Sekolah PKBM Wiyata Utama adalah salah satu sekolah yang belum memiliki ruang baca yang layak dari segi pencahayaan, dikarenakan kurangnya intensitas lampu yang dimiliki pada ruang baca di sekolah ini. Lampu yang akan digunakan untuk penataan pencahayaan adalah lampu jenis LED.

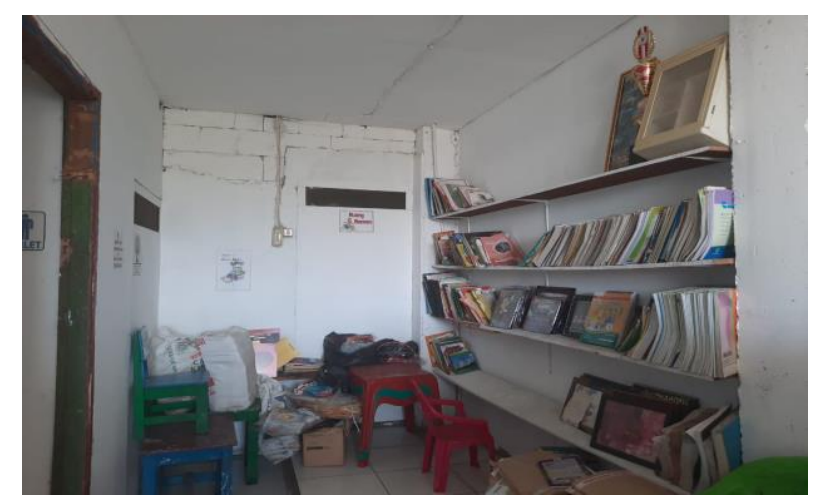

Gambar 1. Kondisi ruang baca di sekolah PKBM Wiyata Utama sebelum dilakukan penataan

Berdasarkan hasil identifikasi permasalahan di sekolah PKBM Wiyata Utama diperoleh beberapa hal yang perlu dilakukan yaitu pembekalan dalam penerapan sistem penerangan dengan lampu LED untuk mendukung peningkatan fungsi ruang baca dan penataan rak buku karena banyak buku yang berserakan sehingga tidak nyaman untuk dilihat. Tujuan kegiatan untuk membuat pencahayaan dan penataan ruang baca di sekolah PKBM Wiyata Utama agar terlihat indah, nyaman dan pencahayaan yang baik agar minat baca siswa-siswi dan guru makin meningkat serta 
dapat mengembangkan dan menambah wawasan serta memperkaya ilmu.

\section{METODE}

Kegiatan dilaksanakan pada tanggal 24 Februari 2021 yang berupa pemaparan desain ruang baca dengan jumlah peserta yang hadir terdiri dari 49 siswa sekolah PKBM, 89 mahasiswa, dan 20 orang dari tamu undangan dan guru-guru pihak sekolah. Pemaparan dilaksanakan secara online karena pada masa pandemi Covid19. Metode yang digunakan dalam kegiatan terdiri dari 4 tahap utama.

\section{Tahap Identifikasi Masalah}

Pada tahapan ini dilakukan dengan cara survei ke sekolah PKBM Wiyata Utama kemudian menganalisis permasalahan ada di sekolah. Hasil survei lapangan ditunjukkan pada gambar 1 . Setelah mendapatkan hasil survei dilakukan rapat tim untuk menentukan langkah-langkah selanjutnya.

\section{Tahap Pemaparan}

Metode pemaparan dilakukan secara online terkait dengan sistem pencahayaan dan penataan ruang baca yang baik untuk meningkatkan minat baca siswa di sekolah PKBM Wiyata Utama. Target utama peserta dalam kegiatan ini adalah para siswa dengan kemauan belajar serta bersedia untuk mengikuti materi yang disampaikan selama kegiatan berlangsung.

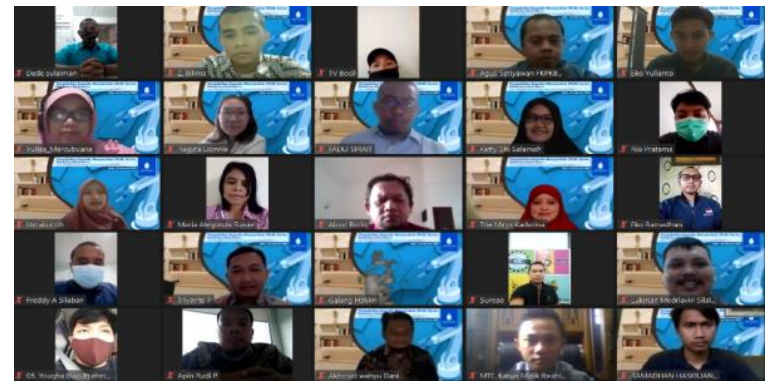

Gambar 2. Foto saat pemaparan kegiatan

Foto pemaparan kegiatan dengan menggunakan zoom meeting yang ditunjukkan pada gambar 2. Tahap pemaparan ini adalah penjelasan terhadap desain penataan ruang baca yang ditunjukkan pada gambar 3. Pengenalan konsep penerangan dan penataan ruang baca dengan cara pemaparan sistem pencahayaan yang sesuai standar dan perbaikan ruang baca yang berada di sekolah PKBM Wiyata Utama.
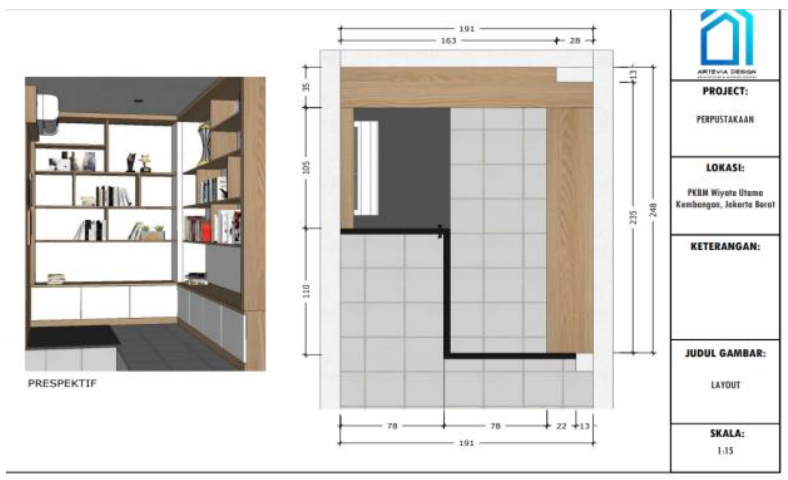

Gambar 3. Desain layout ruang baca

\section{Tahap Pelaksanaan}

Setelah tahap pemaparan selanjutnya adalah tahap implementasi. Tahap implementasi atau pelaksanaan penataan ruang baca mengacu pada desain yang telah disampaikan. Proses pelaksanaan penataan ditunjukkan pada gambar 4 . 
925 Pelatihan Penataan Dan Penerangan Ruang Baca Di Sekolah PKBM Wiyata Utama - Triyanto Pangaribowo, Trie Maya Kadarina, Fadli Sirait, Akhmad Wahyu Dani, Fina Supegina

DOI: https://doi.org/10.31004/abdidas.v2i4.391

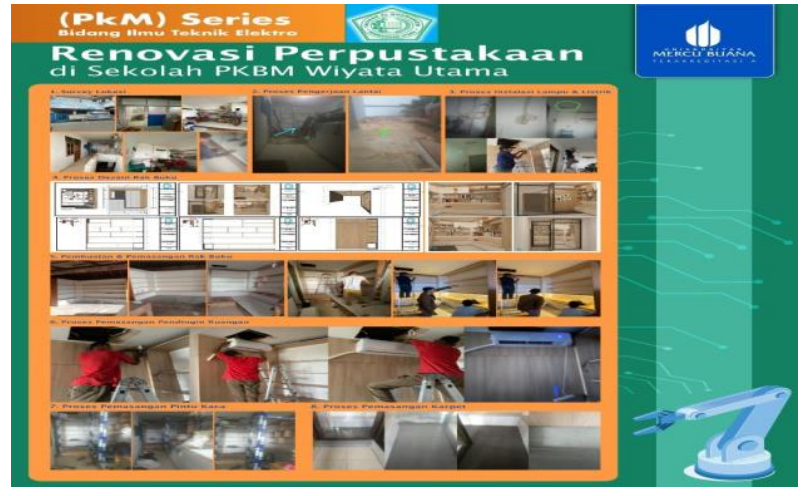

Gambar 4. Kegiatan Penataan Ruang Baca

\section{Tahap Evaluasi Kegiatan}

Tahapan evaluasi kegiatan dilakukan dengan pengisian kuisioner oleh peserta kegiatan untuk keperluan evaluasi program kegiatan yang telah dilakukan. Kuisioner dilakukan secara online karena masih dalam masa pandemi Covid - 19 . Kuisioner terdiri dari 4 skala yaitu sangat tidak setuju (STS), tidak setuju (TS), setuju (S), dan sangat setuju (SS). Berikut ini pertanyaan dalam kuisioner mengenai evaluasi kegiatan antara lain Relevansi keahlian dengan penyelesaian masalah, pemanfaatan teknologi tepat guna, peningkatan pengetahuan, Manfaat kegiatan dalam peningkatan pengetahuan, Manfaat kerjasama kampus dengan mitra dalam kegiatan pengabdian bagi masyarakat.

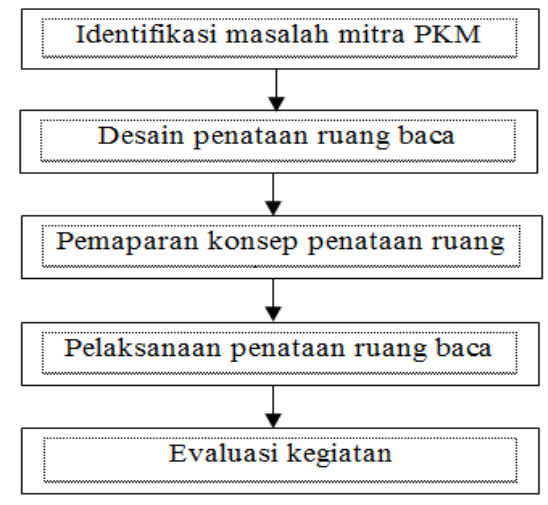

Gambar 5. Bagan Alur Kegiatan

\section{HASIL DAN PEMBAHASAN}

Penataan ruang baca dilaksanakan sesuai dengan desain gambar yang sudah dibuat, terutama pada sisi dinding dan instalasi penerangan dan listrik. Hasil desain ruang baca ditunjukkan pada gambar 6.
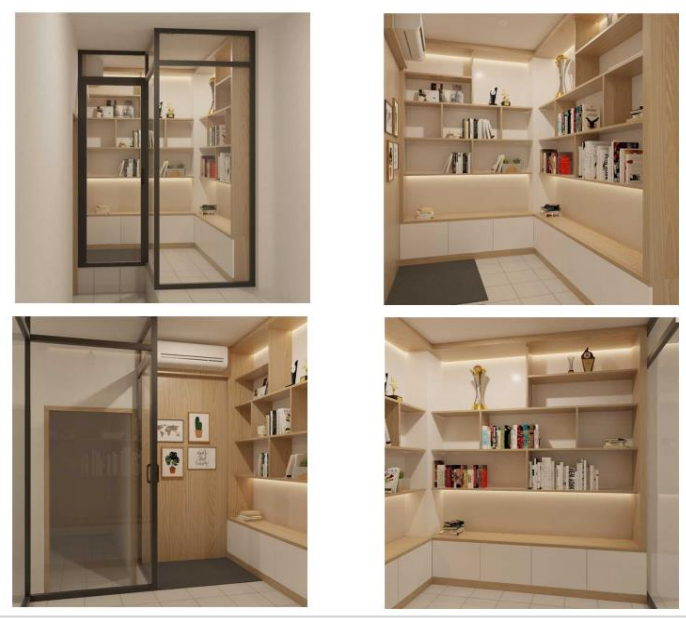

Gambar 6. Desain ruang baca tampak depan.

Evaluasi setelah pelaksanaan rangkaian program kegiatan pengabdian kepada masyarakat yang berupa hasil kuisioner ditunjukan pada gambar 7 sampai 11 .

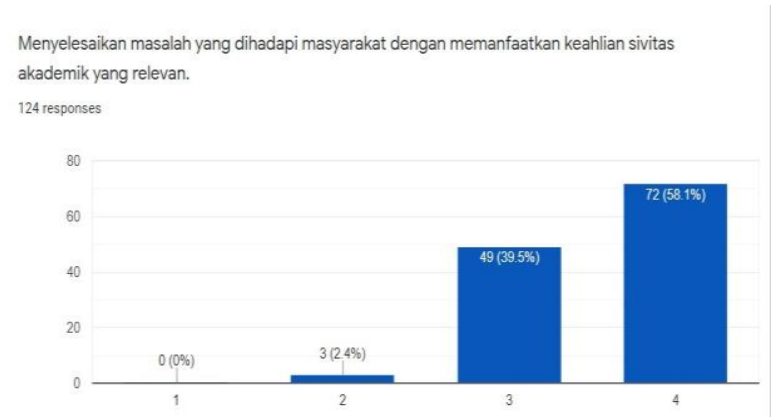

Gambar 7. Kuisioner mengenai relevansi keahlian dengan penyelesaian masalah

Gambar 7 menunjukkan hasil kuisioner yang dilakukan terhadap 124 responden dengan 
926 Pelatihan Penataan Dan Penerangan Ruang Baca Di Sekolah PKBM Wiyata Utama - Triyanto Pangaribowo, Trie Maya Kadarina, Fadli Sirait, Akhmad Wahyu Dani, Fina Supegina

DOI: https://doi.org/10.31004/abdidas.v2i4.391

hasil $58,1 \%$ menjawab sangat setuju bahwa kegiatan yang dilaksanakan relevan dengan keahlian sivitas untuk penyelesaian permasalahan. Sedangkan $35,5 \%$ menjawab setuju memiliki relevansi. Responden menyarankan kegiatan pengabdian kepada masyarakat oleh kampus untuk selalu dilakukan agar permasalahan di masyarakat mendapat solusi terbaik. Gambar 8 menunjukkan hasil kuisioner mengenai pemanfaatan teknologi tepat guna.

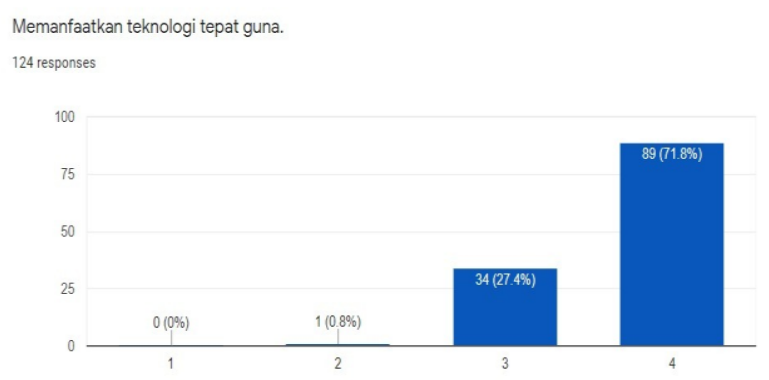

Gambar 8. Hasil kuisioner mengenai pemanfaatan teknologi tepat guna

Penilaian responden menunjukkan $71,8 \%$ sangat setuju bahwa dalam kegiatan pengabdian masyarakat ini telah sangat baik dalam menerapkan teknologi tepat guna untuk menyelesaikan permasalahan.

Gambar 9 menunjukkan hasil kuisioner untuk mendapatkan informasi mengenai kegiatan yang telah dilakukan sangat bermanfaat dalam peningkatan pengetahuan. $81,5 \%$ responden menyatakan sangat setuju bahwa kegiatan membantu untuk peningkatan pengetahuan.

Sedangkan $17,7 \%$ menyatakan setuju kegiatan memiliki manfaat yang baik untuk meningkatkan pengetahuan. Sehingga dapat disimpulkan bahwa kegiatan pengabdian masyarakat ini memiliki manfaat yang tinggi dalam transfer pengetahuan untuk masyarakat.

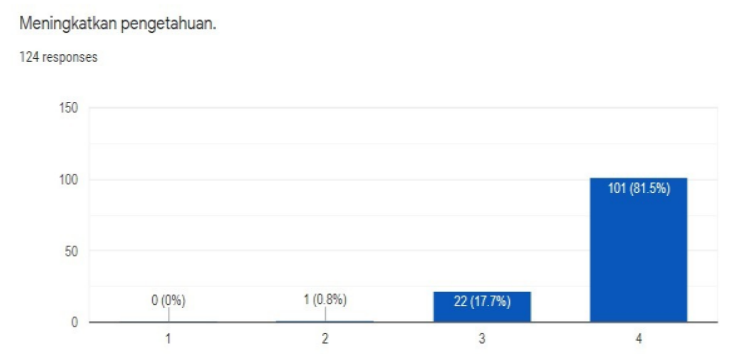

Gambar 9. Hasil kuisioner mengenai peningkatan pengetahuan

Gambar 10 adalah hasil kuisioner untuk mengetahui manfaat kegiatan bagi pengembangan ilmu pengetahuan dan teknologi dengan 70,2 \% responden menjawab sangat setuju bahwa kegiatan bermanfaat bagi pengembangan ilmu pengetahuan dan teknologi dan 29,8\% menjawab setuju kegiatan memiliki manfaat yang baik.

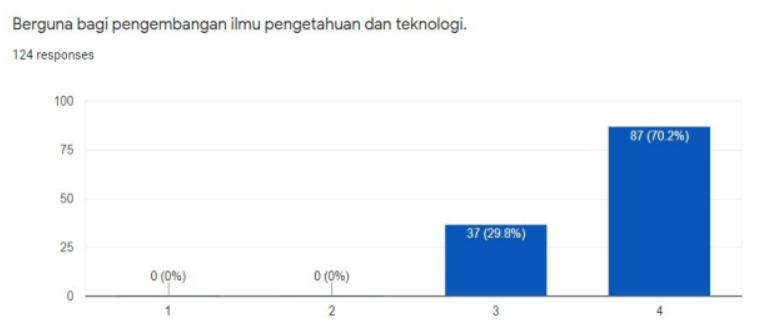

Gambar 10. Hasil kuisioner mengenai manfaat kegiatan untuk pengembangan ilmu pengetahuan dan teknologi

Gambar 11 adalah hasil kuisioner mengenai manfaat kerja sama yang telah dilakukan Universitas Mercu Buana Jakarta dalam program kegiatan pengabdian masyarakat. Hasil evaluasi menunjukkan bahwa kegiatan sangat bermanfaat bagi masyarakat hal ini ditunjukkan dengan jawaban sangat setuju oleh responden sebesar $63,7 \%$ sedang $35,5 \%$ menjawab setuju memiliki 
927 Pelatihan Penataan Dan Penerangan Ruang Baca Di Sekolah PKBM Wiyata Utama - Triyanto Pangaribowo, Trie Maya Kadarina, Fadli Sirait, Akhmad Wahyu Dani, Fina Supegina

DOI: https://doi.org/10.31004/abdidas.v2i4.391

manfaat yang baik. Pihak sekolah juga menyarankan agar kegiatan pengabdian ini dapat dilakukan secara berkelanjutan untuk memberikan solusi bagi masyarakat.

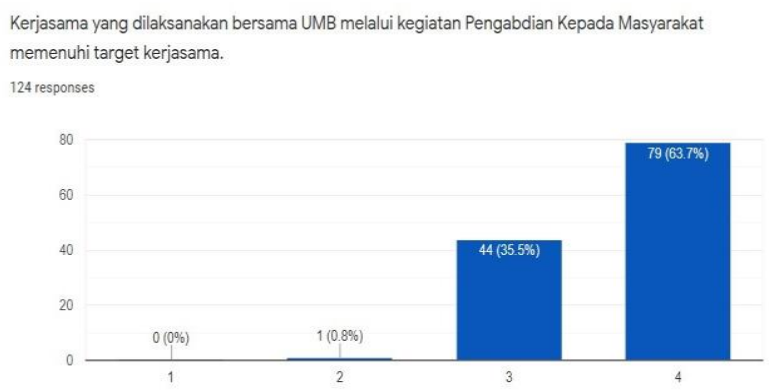

Gambar 11. Hasil kuisioner mengenai manfaat kegiatan bagi masyarakat

\section{SIMPULAN}

Adapun kesimpulan dari kegiatan yang telah dilakukan adalah sebagai berikut:

1. Relevansi keahlian sivitas dengan penyelesaian permasalahan dinilai sudah sangat baik yang ditunjukkan $58,1 \%$ menjawab sangat baik dan $35,5 \%$ menjawab memiliki relevansi baik.

2. Secara keseluruhan, peserta pelatihan di dominasi oleh individu yang belum mengerti dengan penataan ruang baca mulai dari sistem penerangan dan rak buku yang baik, tetapi mereka sangat menyukai hal tersebut, sehingga menambah wawasan dari siswa/i. Hasil kuisioner menunjukkan $81,5 \%$ kegiatan sangat membantu untuk meningkatkan pengetahuan.

3. Kerja sama perguruan tinggi dalam hal ini Universitas Mercu Buana dengan Sekolah PKBM Wiyata Utama sangat bermanfaat bagi penyelesaian sekolah terutama untuk ruang baca. Hal ini ditunjukkan dengan hasil kuisioner terhadap responden dengan jawaban sangat bermanfaat $63,7 \%$.

\section{UCAPAN TERIMA KASIH}

Terimakasih kami ucapkan kepada Lembaga Pengabdian kepada Masyarakat Universitas Mercu Buana Jakarta dan Sekolah PKBM Wiyata Utama yang telah mendukung penuh untuk kelancaran pelaksanaan program pengabdian masyarakat. Serta teman-teman dosen yang telah membantu upaya pelaksanaan kegiatan mulai dari survei sampai pelaksanaan.

\section{DAFTAR PUSTAKA}

Agam, B., Yushardi, Y., \& Prihandono, T. (2015). Pengaruh Jenis Dan Bentuk Lampu Terhadap Intensitas Pencahayaan Dan Energi Buangan Melalui Perhitungan Nilai Efikasi Luminus. Jurnal Pembelajaran Fisika Universitas Jember, 3(4), 138749.

Hidayatullah, I. (2017). Ruang Personal Pemustaka di Ruang Baca Perpustakaan Umum Kota Malang. Jurnal Mahasiswa Jurusan Arsitektur.

Kurniasih, S., \& Saputra, O. (2019). Evaluasi Tingkat Pencahayaan Ruang Baca Pada Perpustakaan Universitas Budi Luhur, Jakarta. Jurnal Arsitektur ARCADE, 3(1), 73. https://doi.org/10.31848/arcade.v3i1.136

Muhriani, Umran, L. O. M., \& Abdullah, M. Z. (2016). Fungsi Ruang Baca di Perpustakaan dan Arsip Daerah Provinsi Sulawesi Tenggara. Jurnal Ilmu Komunikasi UHO, 1(3), 1-14.

Susanti, E., \& Budiono. (2014). Desain Interior Perpustakaan sebagai Sarana Edukasi dan Hiburan dengan Konsep Post Modern. Jurnal Sains Dan Seni Pomits, 3(1), 10.

Winardi, B. (2018). Penghematan Biaya Listrik Dengan Memanfaatkan Lampu LED Di Rumah Tangga (pp. 381-385). pp. 381-385.

Wiyanti, N., \& Martiana, T. (2015). Dengan Kelelahan Mata Pada Pengrajin Batik Tulis. The Indonesian Journal of Occupational Safety and Health, 4(2), 144-154. 